\title{
Patterns of suspected wheat-related allergy: a retrospective single-centre case note review in 156 patients
}

\author{
Morten J Christensen", Esben Eller, Charlotte G Mortz and Carsten Bindslev-Jensen
}

\begin{abstract}
Background: Allergy to wheat can present clinically in different forms: Sensitization to ingested wheat via the gastrointestinal tract can cause traditional food allergy or in combination with exercise, Wheat-Dependent ExerciseInduced Anaphylaxis (WDEIA). Sensitization to inhaled wheat flour may lead to occupational rhinitis and/or asthma.

Methods: We retrospectively reviewed the case notes of 156 patients (age $0.7-73.3$ years) with a case history of wheat allergy. The population was divided into three groups, 1: Wheat allergy elicited by ingestion, 2: By inhalation and 3: WDEIA. All patients were examined with detailed case history, specific lgE (slgE), Skin Prick Test (SPT) and wheat challenge (nasal or oral \pm exercise). Details of the case history were extracted from the patients' case records.

Results: Group 1: Twenty one of 95 patients were challenge positive (15 children, 6 adults). All children had atopic dermatitis, and most (13/15) outgrew their wheat allergy. Most children (13/15) had other food allergies. Challenge positive patients showed significantly higher levels of slgE to wheat and significantly more were SPT positive than challenge negative.

Group 2: Eleven out of 13 adults with occupational asthma or rhinitis were challenge positive. None outgrew their allergy. Seven had positive slgE and 10 had positive SPT to wheat.

Group 3: Ten of 48 (adolescent/adults) were positive when challenged during exercise. Challenge positive patients showed significantly higher levels of slgE to $\omega$-5-gliadin. The natural course is presently unknown.

Conclusion: Wheat allergy can manifest in different disease entities, rendering a detailed case history and challenge mandatory. Patient age, occupation, concomitant allergies (food or inhalant) and atopic dermatitis are important factors for evaluation.
\end{abstract}

Keywords: Age dependency, Natural course of wheat allergy, Wheat allergy, Wheat challenge, $\omega-5$ gliadin

\section{Introduction}

Wheat proteins can be classified into the albumin and globulin (water/salt-soluble) fraction and the gliadin and glutenin (alcohol and acid/alkali-soluble) fraction (gluten) [1]. Both water/salt-soluble and insoluble proteins have been implicated with in wheat hypersensitivity [2]. Wheat allergy, as a specific immunoglobulin-E (sIgE)mediated reaction to wheat protein, is a complex disease due to the many allergenic components (water soluble and -insoluble) in wheat $[2,3]$. Depending on the route of exposure and underlying immunological mechanisms,

\footnotetext{
* Correspondence: morten.junker.christensen@rsyd.dk

Department of Dermatology and Allergy Centre, Odense Research Center for Anaphylaxis (ORCA), Odense University Hospital, Odense C, 5000 Odense,
} Denmark wheat allergy may manifest clinically in different forms: Sensitization to ingested wheat can cause traditional food allergy and in combination with exercise, WheatDependent Exercise-Induced Anaphylaxis (WDEIA) [3], whereas inhalation of wheat flour can lead to occupational rhinitis and/or asthma [4-6].

Since data on wheat allergy are sparse, the aim of this study was to describe characteristics and clinical outcomes of 156 patients evaluated for a wheat related allergy.

\section{Methods \\ Subjects}

From May 2001 to September 2013, we investigated 156 patients (72 female, 84 male, age 0.7 - 73.4 years) with a

\section{Biomed Central}

(c) 2014 Christensen et al.; licensee BioMed Central Ltd. This is an Open Access article distributed under the terms of the Creative Commons Attribution License (http://creativecommons.org/licenses/by/4.0), which permits unrestricted use, distribution, and reproduction in any medium, provided the original work is properly credited. The Creative Commons Public Domain Dedication waiver (http://creativecommons.org/publicdomain/zero/1.0/) applies to the data made available in this article, unless otherwise stated. 
case history of a type 1 immediate reaction related to wheat ingestion as part of routine clinical care. All data were collected retrospectively and anonymously from medical records by the patients' responsible clinicians. The population was divided into three groups (Figure 1):

1. Case history of an allergic reaction to ingestion of wheat (group 1, $\mathrm{n}=95$ )

2. Case history of an allergic reaction to inhalation of wheat flour (group 2, $\mathrm{n}=13$ ).

3. Case history of an allergic reaction to ingestion of wheat in combination with physical exercise (group $3, \mathrm{n}=48$ )

At the time of consultation in the clinic, all patients had a detailed case history recorded, and underwent clinical examination, measurement of serum sIgE, Skin Prick Test (SPT) followed by wheat challenge (nasal or oral) as part of routine clinical practice by medical staff involved in their care. If judged relevant based on case history and test results, wheat challenge was also performed during physical exercise.

\section{Serology and skin prick test}

For measurements of serum levels of sIgE to wheat (f4) and grass (g6) were analysed before challenge (ImmunoCAP system (ThermoFischer, Uppsala, Sweden). In group 3 (WDEIA) sIgE to $\omega$-5-gliadin (f416) was also measured. Positive results were defined as $\geq 0.35 \mathrm{kU} / \mathrm{l}$.
SPT with raw wheat, rye, oat and barley together with standard inhalant panel (ALK-Abello, Copenhagen, Denmark) was performed on the forearm of the patient. A positive SPT was defined as a wheal size of $\geq 3 \mathrm{~mm}$ larger than the negative control. Histamine dihydrochloride (10 mg/ml, ALK, Copenhagen, Denmark) and physiological saline were used as positive and negative controls. Antihistamines and other drugs interfering with SPT were discontinued at least three days prior to testing. Specific $\mathrm{IgE}$ and SPT were performed less than one year prior to challenge.

\section{Challenge procedure}

The challenge procedure was according to the daily routine in the Allergy Centre, including termination of interfering drugs three days prior to challenge. Informed consent was obtained verbally from all patients or - in case of minors - from parents.

A positive challenge was defined according to Sampson's grading scale for anaphylaxis [7].

\section{Oral wheat challenge}

To determine the clinical threshold to wheat an open food challenge (OFC) or double-blind, placebo-controlled food challenge (DBPCFC) was performed. Material for DBPCFC was produced by masking $25 / 50$ gram wheat or placebo in a chocolate bar weighing in total 155-175 gram [8]. Increasing doses of $0.5,1,4,8,16,32$ and $95-115$ gram bar were given with 30 minutes interval. In OFC increasing doses of $0.25,0.5,1,2,4,8$ and 9.25 gram to a cumulative

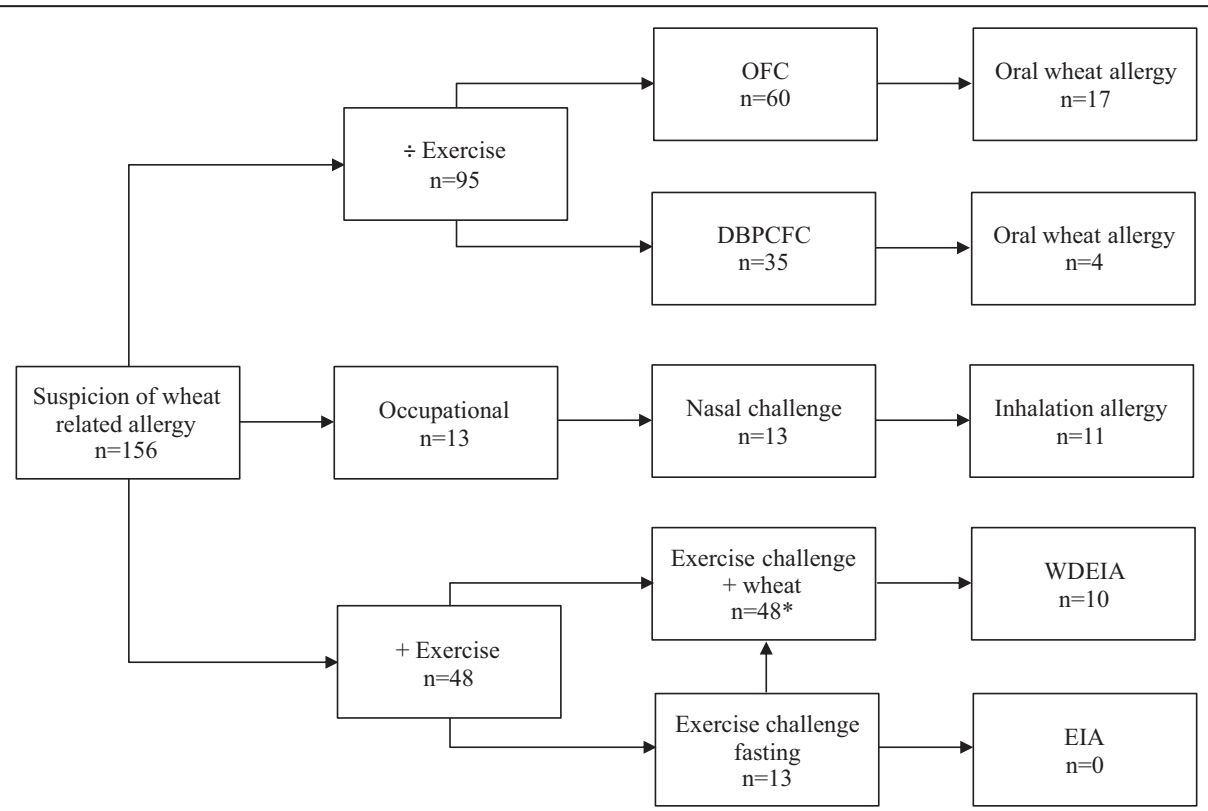

Figure 1 Flowchart of patients with suspected wheat related allergy. OFC: Open food challenge. DBPCFC: Double-blind, placebo-controlled food challenge. WDEIA: Wheat-Dependent Exercise-Induced Anaphylaxis. EIA: Exercise Inducecd Anaphylaxis. *7 patients were also challenged with aspirin and/or alcohol. 
dose of 25 gram were administered at 30 minutes interval. In selected cases and based on case-history the cumulative dose was increased up to 125 gram. The individual doses of wheat flour were mixed with, for example, yoghurt. Challenge was terminated when the patient developed signs $\geq$ grade 2 [7], relevant treatment was instituted and the patient kept under strict surveillance according to the Centre's guidelines.

\section{Nasal challenge}

Thirty mg of placebo flour (potato or maize) was administrated single blinded via a spatula and sniffed into one nostril. After 10 minutes, the procedure was repeated in the opposite nostril with $30 \mathrm{mg}$ of the (most often) raw wheat. A negative outcome was repeated up to 3 times for verification. Symptoms and signs monitored during challenge were itching, sneezing, watery secretion and drop in FEV1.

\section{Exercise and food challenge}

OFC plus exercise included a combination of ingestion of a wheat containing food with physical exercise on a treadmill (Technogym Excite + Run Now 900). As standard, the patients were given 3 slices of commercially available wheat toast bread, equivalent to 44 grams of wheat flour The wheat product was ingested 30 minutes before the exercise challenge, (in selected patients extended up to 180 minutes). Aspirin (500 mg) and/or alcohol (serum level $0.5^{0} / 00$ ) were added in 5 patients and the challenge repeated on a separate day.

The exercise challenge protocol was modified from the protocol developed by Bruce et al. [9]. Challenges started with a 20-30 minute aerobic phase adapted to individual physical ability. Thereafter, based on the aerobic workload, a multistage exercise test was performed, where both pace and inclination were increased every minute to physical fatigue. Each multistage intensity cycle was followed by one minute of light workload ( $5 \mathrm{~km} / \mathrm{h}$ and no inclination). Serum lactate was measured (Lactate Pro, Arkray, Kyoto, Japan) after the multistage exercise challenge at physical fatigue.

\section{Statistics}

Statistical analyses were performed using statistical software (STATA version 11.1, StataCorp, College Station, TX, USA). For the purpose of statistical analysis, sIgE values $<0.35$ were assigned a value of zero. Statistical significance was calculated using the t-test and Fischer's exact test and defined for all comparisons by $\mathrm{p}$ values $<0.05$. Sensitivity and specificity of sIgE to wheat for patients with a respective wheat related allergy were examined by receiveroperator characteristics (ROC)-curves [10].

\section{Results}

Characteristics of the study population $(\mathrm{n}=156)$ and results from the challenges (42 positive) are presented in Table 1. All positive challenges included objective signs (Table 1$)$, most were grade $2(81 \%)$, grade $3(14 \%)$ and grade 4 (5\%) according to Sampson [7] and all placebo challenges were negative $(n=35)$.

\section{Oral wheat allergy (Group 1)}

Twenty-one of the 95 who performed oral wheat challenges were positive; 15 of 48 were in children below 6 years of age (31\%). Children (both challenge positive and negative) had significantly $(\mathrm{p}<0.01)$ more often atopic diseases, especially atopic dermatitis, than adults (96\% vs. $42 \%$ ), Table 1. Ninety-four percent of all children and $87 \%$ of wheat challenge positive children were allergic (proven by challenge) to a least one other food. In adults only $11 \%$ had another challenge proven food allergy ( $\mathrm{p}<0.01)$. The clinical threshold for elicitation of objective signs varied between $25 \mathrm{mg}$ and $50 \mathrm{~g}$ (Figure 2). We found no correlation between age of the patient and threshold and only a weak correlation between level of $\operatorname{sIgE}$ and threshold $(r=0.13)$. According to the ROCcurve analysis (Figure 3), the cut off value for sIgE to wheat producing the best sensitivity $(20 \%)$ and specificity (98\%) was $47.4 \mathrm{kU} / \mathrm{l}$.

Challenge positive patients showed significantly higher levels of SIgE and larger SPT wheals to wheat, than the challenge negative group, (Figure 4). We found no significant difference between challenge positive and negative children aged $0-6$ years and sensitization to grass pollen. In the challenge negative group aged 7-18 years, 9 of 11 (82\%) (mean 36.6, range [0-80.0 kU/l]) were sensitized to grass. No significant differences were found among the adults.

In order to monitor the natural course of their allergy (persistence or development of tolerance) fourteen patients underwent more than one challenge: All children except two outgrew their wheat allergy (mean age 3.6 years). The median time between diagnosis and acquisition of tolerance was 23 months. Based upon telephone interview all adults had a persistent wheat allergy, none were re-challenged.

\section{Inhalation allergy (Group 2)}

All patients tolerated ingestion of cereal foods and no patient had a history of oral wheat allergy in childhood. Four patients reacted both to wheat and to rye or durum.

All challenge positive patients developed itching, serial sneezes and rhinorrhoea within 10 minutes after challenge with wheat. Two patients (No. 96 and No. 101) developed dyspnoea and a significant decrease $(\geq 20 \%)$ in 
Table 1 Challenge data and patients characteristics

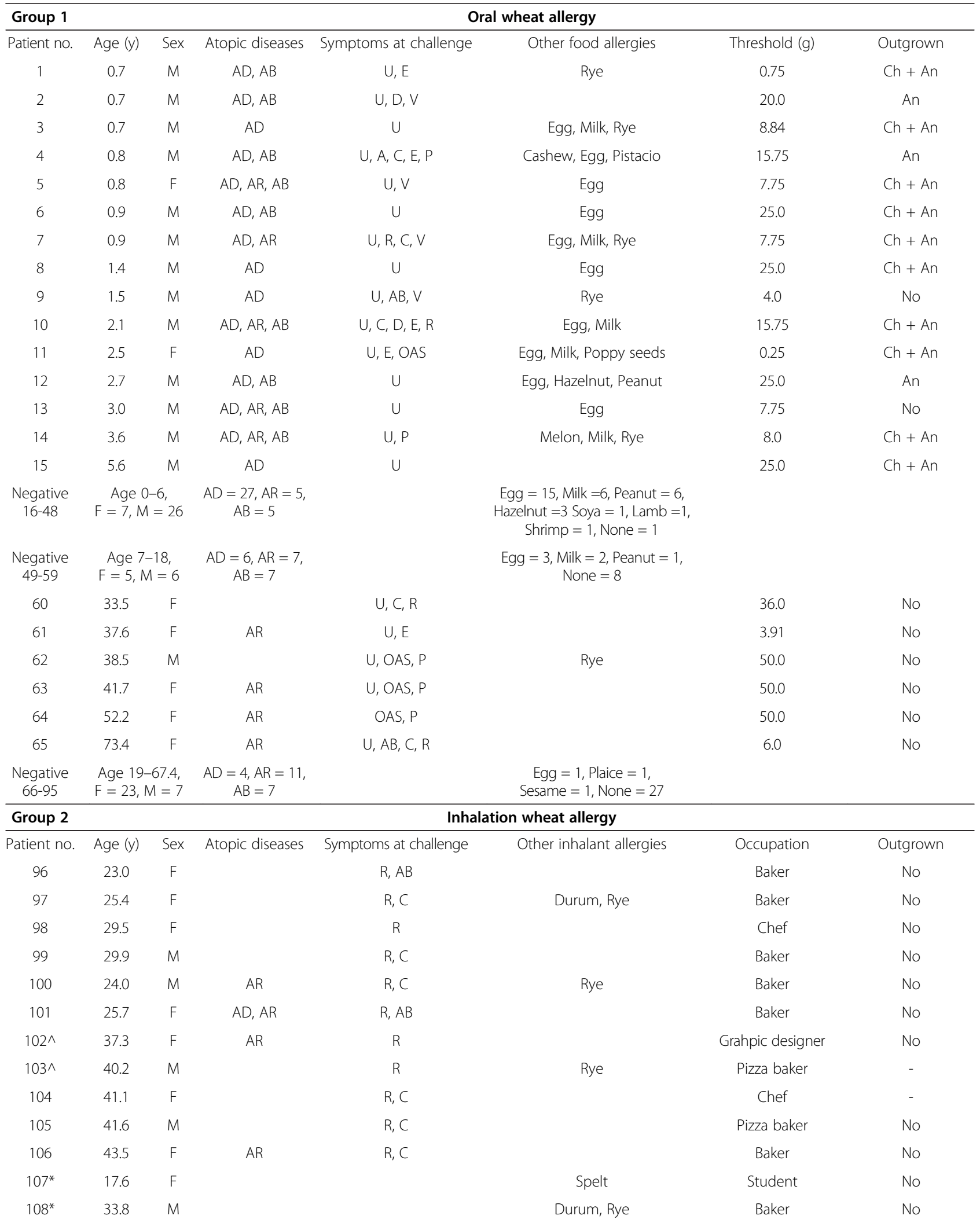


Table 1 Challenge data and patients characteristics (Continued)

\begin{tabular}{|c|c|c|c|c|c|c|c|}
\hline \multirow{2}{*}{$\begin{array}{l}\text { Group } 3 \\
\text { Patient no. }\end{array}$} & \multicolumn{7}{|c|}{ Wheat dependent exercise induced anaphylaxis } \\
\hline & Age (y) & Sex & Atopic diseases & Symptoms at challenge & slgE to $\omega-5$ gliadin $(\mathrm{kUI} / \mathrm{l})$ & Challenge dose (g) & Serum lactate $(\mathrm{mM})$ \\
\hline 109 & 23.0 & M & & U & 14.9 & 44.0 & 11.6 \\
\hline 110 & 27.1 & $\mathrm{~F}$ & $A D$ & $U$ & 11.5 & 44.0 & 2.3 \\
\hline 111 & 27.4 & $\mathrm{~F}$ & $A B$ & U & $<0.35$ & 44.0 & 5.9 \\
\hline 112 & 29.7 & $\mathrm{~F}$ & & $U, A$ & $<0.35$ & 44.0 & 2.3 \\
\hline 113 & 32.4 & $\mathrm{~F}$ & & U & $<0.35$ & 44.0 & 12.6 \\
\hline 114 & 38.1 & $\mathrm{~F}$ & & U & 29.4 & 14.7 & 3.4 \\
\hline 115 & 41.7 & M & & U & 36.6 & 44.0 & 3.1 \\
\hline 116 & 42.2 & M & & U & 11.0 & 44.0 & - \\
\hline 117 & 51.2 & M & & U & 22.7 & 44.0 & 4.8 \\
\hline 118 & 67.2 & M & & U & 8.2 & 29.3 & - \\
\hline $\begin{array}{l}\text { Negative } \\
119-123\end{array}$ & $\begin{array}{l}\text { Age } 7- \\
F=2, M\end{array}$ & $\begin{array}{l}\text { 8.9, } \\
=3\end{array}$ & $\begin{array}{c}A D=1, A R=0 \\
A B=1\end{array}$ & & $\mathrm{n}=0 / 5(0 \%)$ & $\begin{array}{l}\text { mean } 49.8 \\
{[44.0-73.0]}\end{array}$ & $\begin{array}{l}\text { mean } 10.0 \\
{[7.1-12.9]}\end{array}$ \\
\hline $\begin{array}{l}\text { Negative } \\
124-156\end{array}$ & $\begin{array}{l}\text { Age 19- } \\
\mathrm{F}=14, \mathrm{M}\end{array}$ & $\begin{array}{l}\text { 63.0, } \\
=19\end{array}$ & $\begin{array}{c}A D=2, A R=9 \\
A B=1\end{array}$ & & $n=20 / 33(61 \%)$ mean $6.7[0-46.7]$ & $\begin{array}{l}\text { mean } 45.4 \\
{[14.3-58.7]}\end{array}$ & $\begin{array}{c}\text { mean } 11.5 \\
{[4.0-18.7]}\end{array}$ \\
\hline
\end{tabular}

FEV1. No significant signs were elicited during placebo challenge.

Specific IgE to grass was detected in 4 challenge positive patients (mean 4.7 range [0-29.2 kU/l] none had symptoms during the grass pollen season.

According to the ROC-curve analysis (Figure 3), the cut off value for sIgE to wheat, producing the best sensitivity (80\%) and specificity (100\%) was $0.6 \mathrm{kU} / \mathrm{l}$, but this calculation is based on two patients in the negative group only.

If re-exposed to wheat flour, all challenge positive patients experienced symptoms of rhinitis, conjunctivitis or asthma. All 13 patients still tolerated ingestion of cereal foods when interviewed 1-11 years later and 5/11 patients had changed occupation.

\section{WDEIA (Group 3)}

All 48 patients had a convincing case-history related to wheat ingestion combined with physical exercise, but only ten were positive in challenge. No patient had a history of oral wheat allergy or symptoms in response to wheat ingestion alone. Diagnosis of cholinergic urticaria or exercise-induced anaphylaxis (EIA) were excluded either by a fasting exercise challenge $(n=13)$ or by the patient case history $(n=35)$.

Three patients were challenge negative to wheat and exercise, but developed a reaction during challenge with either rye (No. 131 and 135) or oats (No.143). No patient experienced hypotension, collapse or shock during or after the exercise challenge, nor were any late reactions reported by patients.

Based on case history, in 4 patients with a negative challenge outcome, a combination of wheat and aspirin (500-1000 mg and in one of the patients also alcohol at a serum level of $0.5 \%$ oo was administrated 1 to 2 hours prior to challenge, again with a negative outcome of the challenge. Although the challenge positive patients had a significantly higher mean value of sIgE to $\omega$-5-gliadin $(13.4 \mathrm{kU} / \mathrm{l}$ compared to $5.8 \mathrm{kU} / \mathrm{l}(\mathrm{p}<0.05)$ in the negative group), the highest measured level was found in a challenge negative patient (No.129). Elevated levels of sIgE to rye and barley were found significantly more often $(\mathrm{p}<0.05)$ among the challenge positive than negative patients.

According to the ROC-curve analysis (Figure 3), the cut off value for sIgE to $\omega$-5-gliadin, producing the best sensitivity (20\%) and specificity (97\%), was $29.4 \mathrm{kU} / \mathrm{l}$. Frequency of sensitization to grass showed no significant difference between the groups. SPT to wheat flour showed no difference between the positive and negative patients, (Figure 4).

Patients with a positive challenge reacted before a rise in serum lactate could be detected and thus ended up with a significantly $(\mathrm{p}<0.01)$ lower serum lactate compared to the negative group.

\section{Discussion}

Wheat allergy is a result of sensitization to wheat proteins with different characteristics (water or alcohol 


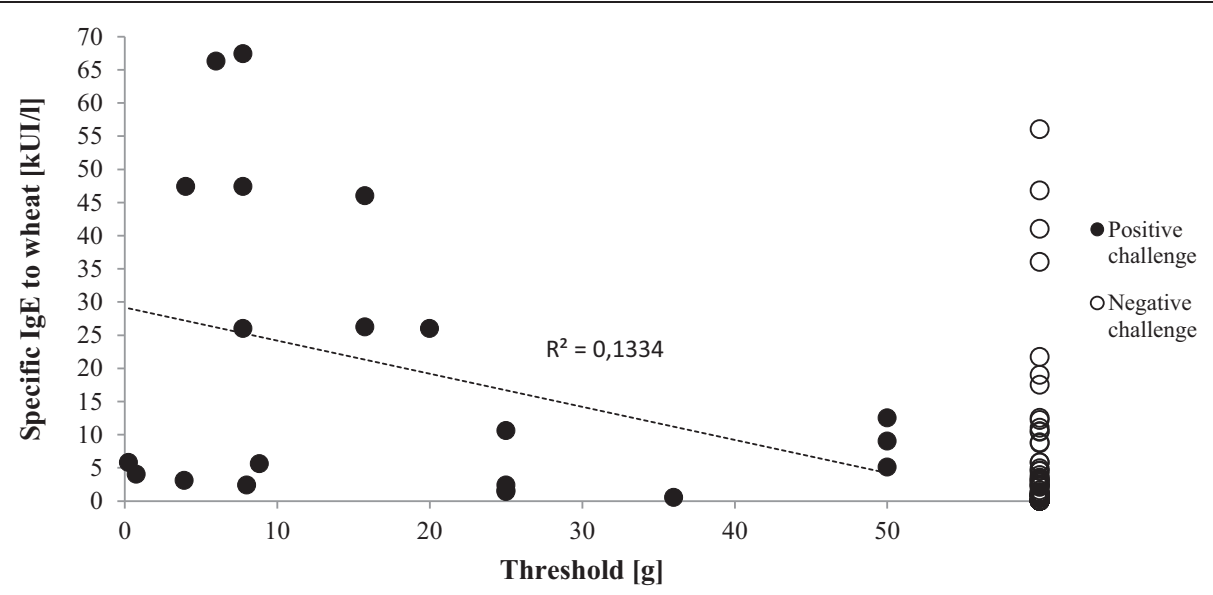

Figure 2 Oral wheat challenge; comparison of specific lgE to wheat and threshold.

solubility, heat resistance) and presents with different clinical phenotypes (urticaria, rhinitis or anaphylaxis), depending on age of patient, concomitant other food or inhalant allergies, atopic dermatitis, route of exposure, sensitization pattern and cofactors such as exercise. A detailed case history and most often a food challenge is therefore mandatory in each patient. The separate disease entities have been published from different centers in detail previously [11-17], but this is the first case series describing differences and similarities between the groups from a single clinical setting.

Age: Children and infants present with symptoms upon oral intake of heat-treated wheat products and without involvement of cofactors, although single cases of exercise induced wheat allergy have been described [18]. Adults, on the other hand, can present with symptoms upon oral intake, by inhalation of raw wheat proteins especially in the occupational setting and after ingestion in combination with cofactors such as physical exercise.

Patient characteristics: The infants and children below the age of 6 years most often present with atopic dermatitis and another challenge proven food allergy, most often to hen's egg (Table 1). Adults with a challenge proven oral wheat allergy characteristically suffer from allergic rhinitis to pollen and also describe oral itching

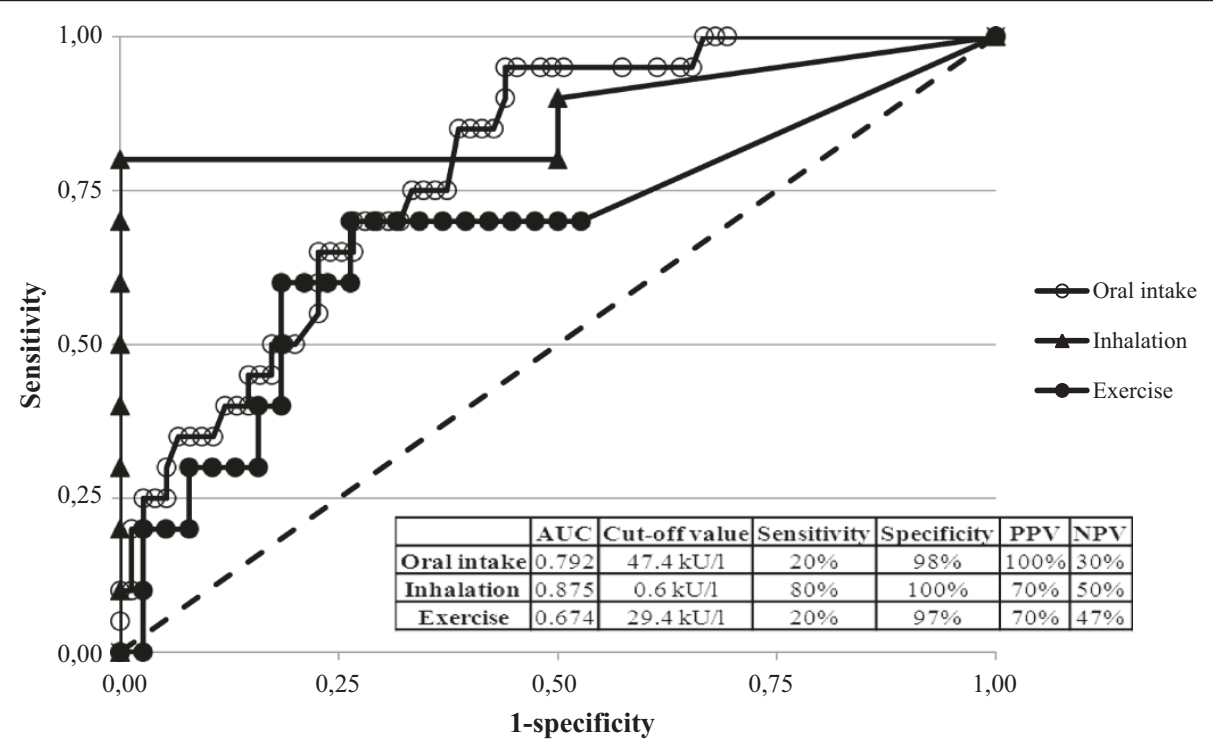

Figure 3 ROC-curves of specific IgE to wheat (oral intake and inhalation) and specific lgE to $\boldsymbol{\omega}-\mathbf{5}$ gliadin (exercise). AUC: Area under the curve, PPV: Positive predictive value, NPV: Negative predictive value. The calculation in the "inhalation" group is only based on two negative challenges. 


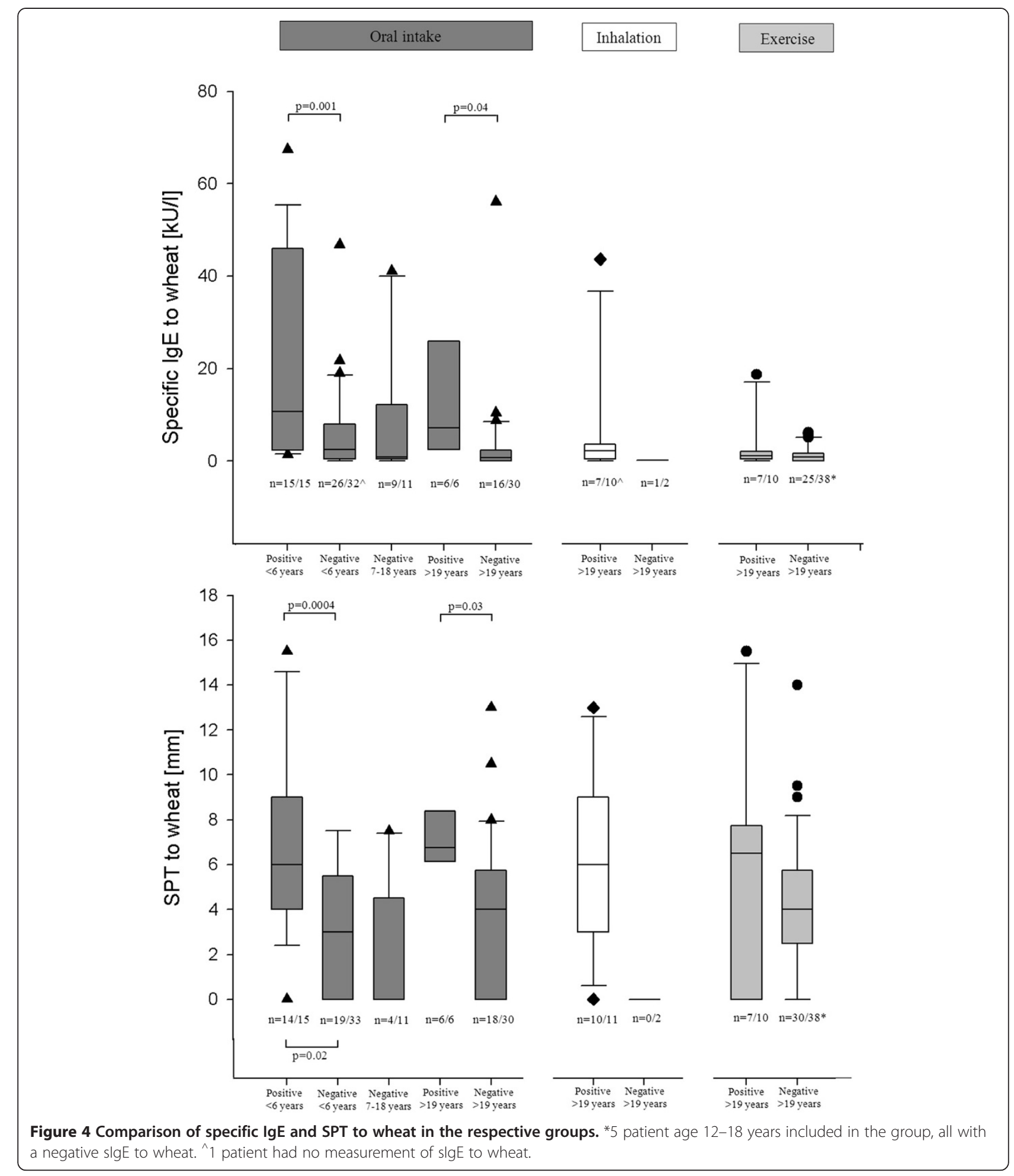

(OAS) upon wheat ingestion (Table 1). Patients with challenge proven reaction to inhaled wheat flour, or who react to ingestion of wheat in combination with physical exercise, are rarely atopic but present with typical case histories. Unfortunately, the patients with negative challenges in all groups present with identical case histories, symptoms and signs with almost the same frequencies except OAS, rendering patient characteristics of little importance for discrimination. The vast majority (87\%) of children with oral wheat allergy develop 
tolerance early in life whereas older children $[19,20]$ and adults [21] (independent of type of wheat allergy) rarely develop tolerance. In a study by Keet et al. [19], 65\% acquired tolerance with a median age of 6.5 years.

Symptoms and signs during challenge: Oral intake of baked wheat almost exclusively elicited generalized acute urticaria in children and adults $[13,20]$. In combination with exercise, however, anaphylaxis can be elicited. As expected, inhalation of raw wheat proteins elicit respiratory symptoms, most of sneezing, but occasionally also asthma [14].

Clinical thresholds: Patients with reactions to inhaled wheat had significantly lower thresholds than the majority of patients reacting to ingested, processed wheat. The thresholds established in group 1 (oral wheat allergy) are in accordance with previously published data in children and adults [13]. An explanation for the many challenge negative patients in group 3 (WDEIA) could be, that clinical thresholds for the majority of patients may be higher than $44 \mathrm{~g}$ of wheat, since we did not find any significant differences between the challenge positive and negative groups concerning case history, levels of sIgE or SPT. The influence of other co-factors such as drugs, alcohol, current infection, temperature, stress, hormonal changes as well as the concept of summation anaphylaxis diminishing the clinical threshold needs further investigation [22]. An interesting and as yet unpublished finding in group 3 (WDEIA) is that a clinical reaction take place under aerobic conditions during exercise as a significant $(\mathrm{p}<0.01)$ lower serum lactate was measured in the challenge positive group.

Diagnostic tests: Comparing groups and patients with positive and negative challenges, a positive skin test (size and frequency) to raw wheat discriminates patients with oral and inhalant wheat allergy, but not patients with suspected WDEIA [23,24]. Specific IgE to wheat discriminates the group of challenge positive children and adults with oral wheat allergy from the negative, but with a large overlap between the groups (Figure 4). The level of sIgE to pollen, especially to grass pollen, should be considered a significant confounder as best described by Martens et al. [25]. They challenged a high number of grass pollen patients with elevated levels of sIgE to wheat negative. The level of sIgE to $\omega$-5-gliadin in the group of challenge positive patients with WDEIA is significantly higher than in the negative group, but again with a large overlap and even with negative values in challenge positive patients, as found by Matsuo et al. [26]. Diagnostic precision are thus low for the diagnostic tests, suggesting other allergens may be involved [27]. Measurement of sIgE toward additional wheat related allergens, as described by Pahr et al. [28] and Pastorello et al. [29] might increase the specificity of our sensitization test, but unfortunately serum were not available for retesting.

\section{Conclusion}

Wheat related allergy is a heterogeneous and complex group of diseases, manifesting in different disease entities, rendering a detailed case-history mandatory in each patient. Patient age, occupation and concomitant allergies (food or inhalant) are important factors for evaluation. Diagnostic tests to wheat proteins can be helpful, but a food challenge is required to confirm the diagnosis of a wheat related allergy.

The influence of food matrix, amount and concentration of wheat proteins, the kinetics and underlying mechanisms, as well as a possible role of facilitators need to be addressed further.

\section{Competing interests}

The authors declare that they have no competing interests.

\section{Authors' contributions}

MJC has performed the data analysis and drafted the manuscript and all co-authors (EE, CGM and CBJ) have contributed to conception and design of the study and interpretation and discussion of the results and endorsed the final manuscript. All authors read and approved the final manuscript.

Received: 23 June 2014 Accepted: 6 October 2014

Published: 21 November 2014

\section{References}

1. Battais F, Richard C, Jacquenet S, Denery-Papini S, Moneret-Vautrin DA: Wheat grain allergies: an update on wheat allergens. Eur Ann Allergy Clin Immunol 2008, 40:67-76.

2. Palosuo K: Update on wheat hypersensitivity. Curr Opin Allergy Clin Immunol 2003, 3:205-209.

3. Morita E, Kunie K, Matsuo H: Food-dependent exercise-induced anaphylaxis. J Dermatol Sci 2007, 47:109-117.

4. Brant A: Baker's asthma. Curr Opin Allergy Clin Immuno 2007, 7:152-155.

5. Moscato G, Vandenplas O, Gerth Van Wijk R, Malo JL, Quirce S, Walusiak J, Castano R, De Groot H, Folletti I, Gautrin D, Yacoub MR, Perfetti L, Siracusa A: Occupational rhinitis. Allergy 2008, 63:969-980.

6. Castano R, Malo JL: Occupational rhinitis and asthma: where do we stand, where do we go? Curr Allergy Asthma Rep 2010, 10:135-142.

7. Sampson HA: Anaphylaxis and emergency treatment. Pediatrics 2003, 111:1601-1608.

8. Eller E, Hansen TK, Bindslev-Jensen C: Clinical thresholds to egg, hazelnut, milk and peanut: results from a single-center study using standardized challenges. Ann Allergy Asthma Immunol 2012, 108:332-336.

9. Bruce RA, Blackmon JR, Jones JW, Strait G: Exercising testing in adult normal subjects and cardiac patients. Pediatrics 1963, 32(Suppl):742-756.

10. Perkins NJ, Schisterman EF: The inconsistency of "optimal" cutpoints obtained using two criteria based on the receiver operating characteristic curve. Am J Epidemiol 2006, 163:670-675.

11. Niggemann B, Sielaff B, Beyer K, Binder C, Wahn U: Outcome of doubleblind, placebo-controlled food challenge tests in 107 children with atopic dermatitis. Clin Exp Allergy 1999, 29:91-96.

12. Sicherer SH, Morrow EH, Sampson HA: Dose-response in double-blind, placebo-controlled oral food challenges in children with atopic dermatitis. J Allergy Clin Immunol 2000, 105:582-586.

13. Scibilia J, Pastorello EA, Zisa G, Ottolenghi A, Bindslev-Jensen C, Pravettoni V, Scovena E, Robino A, Ortolani C: Wheat allergy: a double-blind, placebocontrolled study in adults. J Allergy Clin Immunol 2006, 117:433-439.

14. Airaksinen LK, Tuomi TO, Tuppurainen MO, Lauerma Al, Toskala EM: Inhalation challenge test in the diagnosis of occupational rhinitis. Am J Rhinol 2008, 22:38-46. 
15. Dohi M, Suko M, Sugiyama H, Yamashita N, Tadokoro K, Juji F, Okudaira H, Sano Y, Ito K, Miyamoto T: Food-dependent, exercise-induced anaphylaxis: a study on 11 Japanese cases. J Allergy Clin Immunol 1991, 87:34-40.

16. Romano A, Di Fonso M, Giuffreda F, Papa G, Artesani MC, Viola M, Venuti A, Palmieri V, Zeppilli P: Food-dependent exercise-induced anaphylaxis: clinical and laboratory findings in 54 subjects. Int Arch Allergy Immunol 2001, 125:264-272.

17. Aihara Y, Takahashi Y, Kotoyori T, Mitsuda T, Ito R, Aihara M, Ikezawa Z, Yokota S: Frequency of food-dependent, exercise-induced anaphylaxis in Japanese junior-high-school students. J Allergy Clin Immunol 2001, 108:1035-1039.

18. Pacharn $P$, Jirapongsananuruk $O$, Daengsuwan $T$, Vichyanond $P$, Visitsunthorn N: Wheat-dependent, exercise-induced anaphylaxis in Thai children: a report of 5 cases. Asian Pac J Allergy Immunol 2009, 27:115-120.

19. Keet CA, Matsui EC, Dhillon G, Lenehan P, Paterakis M, Wood RA: The natural history of wheat allergy. Ann Allergy Asthma Immunol 2009, 102:410-415.

20. Eigenmann PA, Sicherer SH, Borkowski TA, Cohen BA, Sampson HA: Prevalence of IgE-mediated food allergy among children with atopic dermatitis. Pediatrics 1998, 101:E8.

21. Maghni K, Lemière C, Ghezzo H, Yuquan W, Malo J-L: Airway inflammation after cessation of exposure to agents causing occupational asthma. Am J Respir Crit Care Med 2004, 169:367-372.

22. Ring J, Behrendt $\mathrm{H}$, de Weck A: History and classification of anaphylaxis. Chem Immunol Allergy 2010, 95:1-11.

23. Quirce S, Fernandez-Nieto M, Escudero C, Cuesta J, de Las HM, Sastre J: Bronchial responsiveness to bakery-derived allergens is strongly dependent on specific skin sensitivity. Allergy 2006, 61:1202-1208.

24. Majamaa H, Moisio P, Holm K, Turjanmaa K: Wheat allergy: diagnostic accuracy of skin prick and patch tests and specific IgE. Allergy 1999, 54:851-856.

25. Martens M, Schnoor HJ, Malling HJ, Poulsen LK: Sensitization to cereals and peanut evidenced by skin prick test and specific lgE in foodtolerant, grass pollen allergic patients. Clin Transl Allergy 2011, 1:15.

26. Matsuo H, Dahlstrom J, Tanaka A, Kohno K, Takahashi H, Furumura M, Morita E: Sensitivity and specificity of recombinant omega-5 gliadin-specific lgE measurement for the diagnosis of wheat-dependent exercise-induced anaphylaxis. Allergy 2008, 63:233-236.

27. Matsuo H, Kohno K, Niihara H, Morita E: Specific IgE determination to epitope peptides of omega- 5 gliadin and high molecular weight glutenin subunit is a useful tool for diagnosis of wheat-dependent exercise-induced anaphylaxis. J Immunol 2005, 175:8116-8122.

28. Pahr S, Constantin C, Mari A, Scheiblhofer S, Thalhamer J, Ebner C, Vrtala S, Mittermann I, Valenta R: Molecular characterization of wheat allergens specifically recognized by patients suffering from wheat-induced respiratory allergy. Clin Exp Allergy 2012, 42:597-609.

29. Pastorello EA, Farioli L, Conti A, Pravettoni V, Bonomi S, lametti S, Fortunato D, Scibilia J, Bindslev-Jensen C, Ballmer-Weber B, Robino AM, Ortolani C: Wheat lgE-mediated food allergy in European patients: alpha-amylase inhibitors, lipid transfer proteins and low-molecular-weight glutenins. Allergenic molecules recognized by double-blind, placebo-controlled food challenge. Int arch Allergy Immun 2007, 144:10-22.

doi:10.1186/2045-7022-4-39

Cite this article as: Christensen et al:: Patterns of suspected wheatrelated allergy: a retrospective single-centre case note review in 156 patients. Clinical and Translational Allergy 2014 4:39.

\section{Submit your next manuscript to BioMed Central and take full advantage of:}

- Convenient online submission

- Thorough peer review

- No space constraints or color figure charges

- Immediate publication on acceptance

- Inclusion in PubMed, CAS, Scopus and Google Scholar

- Research which is freely available for redistribution 